\title{
Podcast: new interest in circumcision
}

I

nfant circumcision has become an increasingly sensitive subject in recent years, for both parents and providers. Now less than a third of baby boys in Canada undergo the snip, and many doctors refuse to perform the surgery on the grounds that it's unnecessary. But as circumcision rates have dropped in countries like Canada, demand for the procedure is growing in the developing world as part of efforts to curb HIV.

Vancouver surgeon Dr. Neil Pollock has been training colleagues in Haiti and Rwanda to perform infant circumcision. He reflected on the pendulum swing of interest in the surgery in a podcast interview. - Lauren Vogel, CMAJ

Tune in at Soundcloud.com

CMAJ 2015. DOI:10.1503/cmaj.109-5076

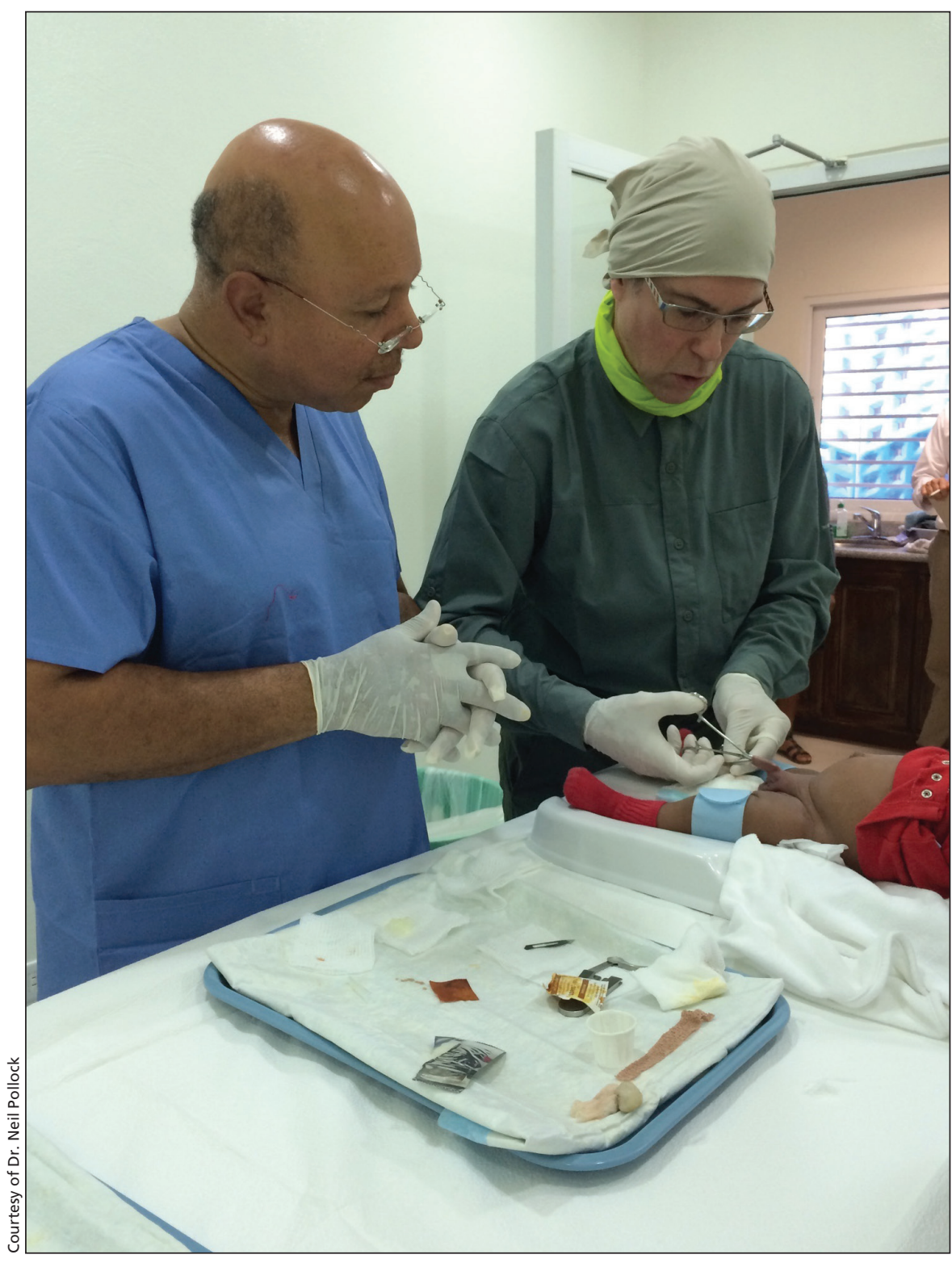

Vancouver surgeon Dr. Neil Pollock trained doctors in Haiti and Rwanda to meet growing demand for infant circumcision. 